\title{
Strong metal-support interaction as activity requirement of palladium-supported tin oxide sol-gel catalyst for water denitration
}

\author{
G. Boskovic $\cdot$ M. Kovacevic $\cdot$ E. Kiss • \\ J. Radnik $\cdot$ M. Pohl $\cdot$ M. Schneider • \\ U. Bentrup $\cdot$ A. Bruckner
}

Received: 18 August 2011/Revised: 19 September 2011/Accepted: 5 December 2011/Published online: 29 February 2012

(C) CEERS, IAU 2012

\begin{abstract}
Two nanocrystalline palladium-supported tin oxide catalysts for water denitration were synthesized by a modified sol-gel technique using appropriate chloride precursors for both support and active phases, and citric acid to tune the rate of hydrolysis and condensation. The difference among sample preparation procedures refers to the moment of the noble metal loading to the support, as well as to the calcination temperature altitude followed. Thus, mesoporous tin oxide was synthesized by a sol-gel method following calcination at $700^{\circ} \mathrm{C}$. The palladium active phase was introduced afterwards by means of palladium chloride solution impregnation, followed by calcination at $400^{\circ} \mathrm{C}$ (sample 1). Alternatively, simultaneous complexation of both metal and support precursors followed by single calcination at $700^{\circ} \mathrm{C}$ was applied for preparation of sample 2 . The former sample showed higher activity and selectivity in hydro-denitration of water model system initially containing $100 \mathrm{ppm}$ of nitrates. This was explained by preferential textural, morphological and structural properties accomplished by early contact of metal and support nanoparticles, while achieved by calcination at high single temperature forcing diffusion of palladium ions into the tin oxide matrix. The outcome is very well distribution of palladium and strong metal-support interaction leading to multivalent tin. This indicates partly reduced tin oxide formation in the course of its
\end{abstract}

G. Boskovic $(\bowtie) \cdot$ M. Kovacevic · E. Kiss

Faculty of Technology, University of Novi Sad,

Bulevar Cara Lazara 1, 21000 Novi Sad, Serbia

e-mail: boskovic@uns.ac.rs

J. Radnik · M. Pohl · M. Schneider - U. Bentrup · A. Bruckner Leibniz Institute for Catalysis, University of Rostock,

18059 Rostock, Germany reduction in hydrogen, which may act as active site in denitration reaction.

Keywords Calcination - Modified sol-gel tin oxidebased catalyst $\cdot$ Multivalent tin

\section{Introduction}

Due to exaggerate usage of fertilizers and other sources of nitrogen-containing pollutants, contamination of groundwater by nitrates $\left(\mathrm{NO}_{3}{ }^{-}\right)$has become a serious problem. Special attention to $\mathrm{NO}_{3}{ }^{-}$level in potable water is a consequence of their excessive toxicity. Removal of highly toxic $\mathrm{NO}_{3}{ }^{-}$in the process of potable water production during the past decade has been focused on catalysis. This is due to several advantages of catalytic over conventional physicochemical and biological denitration technologies, since former have a number of drawbacks. Nevertheless, the problem of catalytic denitration still exists and efforts to find efficient catalyst to reach the USA standard of $10 \mathrm{ppm}$ of $\mathrm{NO}_{3}{ }^{-}$(2.3 ppm calculated by $\left.\mathrm{N} / \mathrm{l}\right)$ are still under progress (EPA 2010).

It is believed that on bimetallic copper-palladium $(\mathrm{Cu}-\mathrm{Pd})$ catalyst using traditional supports, the reaction proceeds through consecutive steps: (a) transformation of $\mathrm{NO}_{3}{ }^{-}$to nitrites $\left(\mathrm{NO}_{2}{ }^{-}\right)$and (b) further reduction of intermediate $\mathrm{NO}_{2}{ }^{-}$to either nitrogen $\left(\mathrm{N}_{2}\right)$ or ammonia $\left(\mathrm{NH}_{4}{ }^{+}\right)$, the latter being an undesired product (Harold et al. 1993). In recent years, monometallic Pd particles on tin oxide $\left(\mathrm{SnO}_{2}\right)$ or titanium oxide $\left(\mathrm{TiO}_{2}\right)$ supports have been proposed as promising catalysts (Gavagnin et al. 2002; D’Arino et al. 2004; Sá et al. 2005, 2006). As suggested, the monometallic mechanism includes a low-coordinated $\mathrm{SnO}_{2}$ site as active center for the first reaction step, while, 
$\mathrm{Pd}$ is responsible for fast "regeneration" of $\mathrm{SnO}_{X}$ active species by providing $\mathrm{H}_{2}$ spillover and further $\mathrm{NO}_{2}{ }^{-}$ reduction (Gavagnin et al. 2002).

Although both unpromoted and promoted $\mathrm{SnO}_{2}$ have been extensively explored in terms of its properties as transparent conducting oxides and solid state gas sensing materials (Fliegel et al. 1994; Dieguez et al. 1996; Freyberger et al. 1989), its catalytic properties have not been as much investigated in contrast to other semiconductors such as, e.g., $\mathrm{TiO}_{2}$.

From the catalytic point of view the interesting properties of $\mathrm{SnO}_{2}$ are related to the fact that tin can exist in two different valence states, namely $2^{+}$or $4^{+}$, making it susceptible to the formation of surface phases with different oxygen composition (Batzill and Diebold 2005).

In general, precipitation (Freyberger et al. 1989), sol-gel synthesis (Ristic et al. 2002), spray-pyrolysis (Caillaud et al. 1992), hydrothermal (Wang et al. 1996) and combustion (Fraigi et al. 1999) methods are commonly used to prepare nanocrystalline $\mathrm{SnO}_{2}$ powder. Recently, "soft chemistry" based on alkoxide precursors has become rather popular in the preparation of a broad spectrum of different catalysts with advantageous properties. The benefits are emphasized by advantageous properties of mesoporous materials, which can be tailored due to well-organized particles of nano-size (Kakihana 1996). On the other hand, traditional methods of catalyst synthesis based on inorganic salts, in principle, are easier to handle and less sensitive to environment, although very much dependent on the type of precursor used (Boskovic et al. 2008; Putanov et al. 1991). Modified sol-gel methods try to avoid the use of costly alkoxide precursors and instead either involve mixing of cheap metal precursors and a strong chelating agent, like an organic polyfunctional acid, or undergo formation of organic polymeric glasses (Kakihana 1996). For $\mathrm{SnO}_{2}$ preparation, a liquid mixing technique including tin chloride $\left(\mathrm{SnCl}_{2}\right)$ and citric acid $\left(\mathrm{C}_{6} \mathrm{H}_{8} \mathrm{O}_{7}\right)$ has been used, which after mixing and further evaporation led to the formation of a highly viscous homogenous polymeric glassy phase and finally to a nanopowder at atomic level. Calcination of the amorphous glassy material allows its quick conversion to $\mathrm{SnO}_{2}$ (Bhagwat et al. 2003).

At the moment there is no clear answer to the question on the mechanism of water denitration over monometallic noble metal-supported catalyst. In this paper, the question on real active site in palladium-supported tin oxide $(\mathrm{Pd} /$ $\mathrm{SnO}_{2}$ ) catalyst was addressed: can $\mathrm{SnO}_{2}$ play a role of catalyst support and at the same time be (a part of) its active phase? And, what is the role of the noble metal in the former? In order to answer these questions joint research were performed at Leibniz-Institut für Katalyse, former Branch Berlin, Germany and at Laboratory for Catalysis, University of Novi Sad-Faculty of Technology, Serbia. In particular, two catalyst samples were synthesized by different methods aiming to give samples with diverse physicochemical and catalytic properties. It is expected that by a process of correlation of these properties the problem of active site will be highlighted.

\section{Materials and methods}

\section{Catalyst preparation}

Two catalyst samples were prepared by methods differing in number of subsequent steps, $\mathrm{pH}$ conditions and the stage of metal function introduction. The support for catalyst 1 was prepared by mixing of $\mathrm{SnCl}_{2} \cdot 2 \mathrm{H}_{2} \mathrm{O}$ (p.a., Centrohem) and $\mathrm{C}_{6} \mathrm{H}_{8} \mathrm{O}_{7}$ (99\%, Alkaloid) previously dissolved in de-ionized water, adjusting a $\mathrm{SnCl}_{2} / \mathrm{C}_{6} \mathrm{H}_{8} \mathrm{O}_{7}$ molecular ratio of 3:5 and $\mathrm{pH} 8$ by addition of $\mathrm{NH}_{4} \mathrm{OH}$. The basic environment aimed at a better control of the rate of organic acid dissociation, easier $(\operatorname{SnOC}(\mathrm{O}) \mathrm{R})_{n^{-}}$ complex formation and lower probability of Sn-entities to agglomerate (Zhang and Gao 2004). The obtained mixture became highly viscous during the slow solvent evaporation at $80^{\circ} \mathrm{C}$ and finally turned into a transparent glass. The glassy state sample was then calcined in air at $700^{\circ} \mathrm{C}$ for $1 / 2 \mathrm{~h}$ in order to transform it to $\mathrm{SnO}_{2}$. The obtained $\mathrm{SnO}_{2}$ support was further wet impregnated with $\mathrm{PdCl}_{2}$ (99\%, Sigma-Aldrich) solution to get the nominal loading of 6 mass\% of $\mathrm{Pd}$ in $\mathrm{Pd} / \mathrm{SnO}_{2}$ catalyst. Next to the impregnation catalyst 1 was dried at $105^{\circ} \mathrm{C}$ overnight and calcined at $400^{\circ} \mathrm{C}$ for $2 \mathrm{~h}$.

Catalyst 2, with the same nominal Pd loading, was prepared by a modified sol-gel method comprising simultaneous complexation of both the catalyst support and active metal precursors. Accordingly, $\mathrm{C}_{6} \mathrm{H}_{8} \mathrm{O}_{7}$ was added to both chloride solutions, $\mathrm{SnCl}_{2} \cdot 2 \mathrm{H}_{2} \mathrm{O}$ and $\mathrm{PdCl}_{2}$, adjusting the same $\mathrm{SnCl}_{2} / \mathrm{C}_{6} \mathrm{H}_{8} \mathrm{O}_{7}$ ratio of 3:5 (Kakihana 1996), followed by merging of the two mixtures. The combined solution was vigorously mixed for $8 \mathrm{~h}$ at $80^{\circ} \mathrm{C}$ until a glassy sample was obtained, followed by $30 \mathrm{~min}$ calcination in air at $700^{\circ} \mathrm{C}$ as described above for the preparation of the support for the catalyst 1 . In such a way the metal component of catalyst 2 has experienced a much higher calcination temperature than in catalyst $1\left(700\right.$ vs. $\left.400^{\circ} \mathrm{C}\right)$.

\section{Catalyst characterization}

Textural characteristics were investigated by means of BET surface area, as well as pore size distribution, mean pore diameter and pore volume, all determined using desorbed amount of nitrogen per catalyst unit volume from desorption part of isotherms. Respective data were obtained by dynamic low temperature adsorption/desorption of 
$\mathrm{N}_{2}$ (LTNA) using $\mathrm{He}$ as carrier gas on a Micromeritics ASAP 2010 apparatus.

The crystalline phase composition was determined by $\mathrm{X}$-ray powder diffraction analysis (XRD) using a STADI $\mathrm{P}$ automated transmission diffractometer (STOE Darmstadt, Germany) with CuKa1 radiation $(\lambda=1.5406 \AA)$ and a $6^{\circ}$ linear position sensitive detector (PSD). The alignment was checked by use of a silicon standard. The data were collected in the 2 Theta range from $5^{\circ}$ to $60^{\circ}$ with a step size of $0.5^{\circ}$ and a measurement time of $50 \mathrm{~s}$ per step. The phase composition of the samples was determined using the program suite Win Xpow by STOE\&CIE with inclusion of the Powder Diffraction File PDF-2 of the ICDD (International Centre of Diffraction Data). The crystallite size of the support was estimated from the XRD patterns according to data of full width at half-maximum using Scherrer's equation.

The palladium loading was measured by a Perkin Elmer ICP-OES Optima 3000XL spectrometer calibrated for the required elements. The catalyst $(5 \mathrm{mg})$ was dissolved in $3 \mathrm{ml}$ nitrohydrochloric acid and $5 \mathrm{ml} \mathrm{HF}$ in a microwave oven (CEM MDS-2000) at 4 bar. The obtained solution was filled up to $100 \mathrm{ml}$ with distilled water. All values were verified by double determination.

$\mathrm{X}$-ray photoelectron spectra were recorded on a $\mathrm{VG}$ ESCALAB 220iXL with $\mathrm{AlK} \alpha$ radiation $(1,486.6 \mathrm{eV})$ under a residual pressure in the analysis chamber below $10^{-7} \mathrm{~Pa}$. The electron binding energy was referenced to the $\mathrm{C} 1 \mathrm{~s}$ peak at $284.8 \mathrm{eV}$. The peaks were fitted by GaussianLorentzian profiles after a Shirley background subtraction. For quantitative analysis, the peak area was divided by the element-specific Scofield factors and the transmission function of the analyzer. The oxidation state of $\mathrm{Sn}$ and $\mathrm{Pd}$ was investigated in both unreduced and reduced $\left(50^{\circ} \mathrm{C}\right.$ in hydrogen flow) samples.

To examine the catalyst morphology as well as to measure the size of metallic particles, both scanning (SEM, JEOL JSM-6460LV, accelerating voltage of $25 \mathrm{kV}$ ) and transmission electron microscopy (TEM) were applied. Before exposure to SEM characterization, solid samples were coated with gold to make them conductive. TEM micrographs were recorded with a CM20 microscope (FEI) equipped with an STwin and LaB6 at $200 \mathrm{kV}$. For EDX measurements without internal standard, a Noran Six analyzer (Thermo) was used with spot sizes of approximately $35 \mathrm{~nm}$.

UV/vis-DRS measurements were performed by a Cary 400 spectrometer (Varian) equipped with a diffuse reflectance accessory (praying mantis, Harrick) and a heatable reaction chamber (Harrick). The samples were measured before and after in situ reduction in $\mathrm{H}_{2}$ flow at $20^{\circ} \mathrm{C}$. Spectra were measured in reflectance mode and converted into the Kubelka-Munk function $\mathrm{F}(\mathrm{R})$ which is proportional to the absorption coefficient for sufficiently low $F(R)$ values. To reduce light absorption, samples were diluted 1:10 using $\mathrm{BaSO}_{4}$ as a standard.

\section{Catalyst activity testing}

Catalyst testing was performed using a $\mathrm{NO}_{3}{ }^{-} / \mathrm{H}_{2} \mathrm{O}$ model system containing initially $100 \mathrm{ppm}$ of $\mathrm{NO}_{3}{ }^{-}$in a slurry semi-batch stirring reactor made of Pyrex glass. In general, $40 \mathrm{mg}$ of catalyst powder was mixed with $70 \mathrm{ml}$ of $\mathrm{H}_{2} \mathrm{O}$ containing $\mathrm{NO}_{3}^{-}$under continuous stirring $\left(350 \mathrm{~min}^{-1}\right.$ ) and hydrogen flow $(60 \mathrm{ml} / \mathrm{min})$. Reaction temperature and pressure were kept constant at $298 \mathrm{~K}$ and 1 bar. During the reaction, $\mathrm{CO}_{2}$ was used as a co-feed to $\mathrm{H}_{2}\left(\mathrm{H}_{2}: \mathrm{CO}_{2}=1: 8\right)$ in order to maintain $\mathrm{pH}$ at 5.4 and to promote selectivity. Before their use in the reaction, both catalyst samples were reduced ex situ in a flow of pure $\mathrm{H}_{2}$ for $2 \mathrm{~h}$ at $25^{\circ} \mathrm{C}$. Liquid phase samples were taken in desired time intervals and $\mathrm{NO}_{3}{ }^{-}, \mathrm{NH}_{4}{ }^{+}$and $\mathrm{NO}_{2}{ }^{-}$ion concentrations were analyzed. For the $\mathrm{NO}_{3}{ }^{-}$and $\mathrm{NH}_{4}{ }^{+}$ions, corresponding ion selective electrodes (Cole-Palmer) with a pH/ion 510 Meter (Oakton Instruments) were used. $\mathrm{NO}_{2}^{-}$concentration was determined photometrically at $\lambda=538 \mathrm{~nm}$ by means of a standard method (JUS ISO 2918, 1991) using a vis-spectrophotometer (Jenway).

\section{Results and discussion}

\section{Catalyst characterization}

\section{Structural investigation}

Evaluation of the XRD profiles given in Fig. 1 clearly indicates $\mathrm{SnO}_{2}$ (rutile tetragonal system) as the only crystalline phase present in catalyst samples regardless of the preparation method. A nano-scale dimension of $\mathrm{SnO}_{2}$ crystallites can be calculated from the XRD-line broadening of both catalyst samples; however, with sample 2 having $\mathrm{SnO}_{2}$ crystallites of much smaller size (Table 1). Such small crystallites of the support phase in sample 2 may favor a higher PdO dispersion, which following the catalyst reduction should lead to metallic particles of lower size compared to sample 1 . In addition there is a broad peak at about $2 \theta=10^{\circ}$ which is an indication for the presence of some amorphous material in sample 2 . Reflections of crystalline Pd are hardly visible in Fig. 1. This may be due to small crystallite size of Pd (Table 1).

XPS results of calcined and reduced samples are presented in Fig. 2 and in terms of their Pd3d and Sn3d electron binding energies in Table 2. For sample 1 two $\mathrm{Pd}$ states are observed before and after hydrogen treatment. For the as-prepared sample 1 the dominating state at 


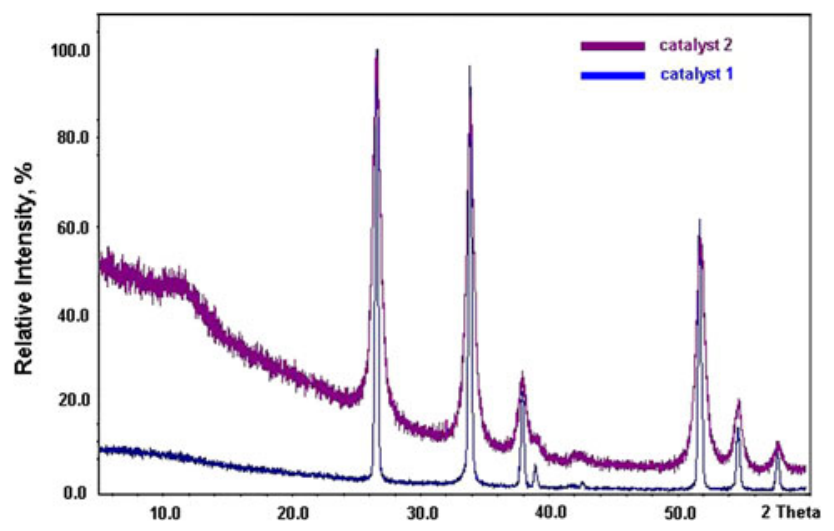

Fig. 1 XRD patterns of catalyst samples

$337.4 \mathrm{eV}$ correlates with $\mathrm{Pd}^{2+}$, whereas the other weak peak at $336.1 \mathrm{eV}$ might be due to partially oxidized Pd (Fig. 2a). For Sn two states were observed before the treatment in $\mathrm{H}_{2}$ (Fig. 2b): the peak at $486.9 \mathrm{eV}$ correlates with $\mathrm{SnO}_{2}$, the shoulder at $485.6 \mathrm{eV}$ may arise from $\mathrm{Sn}^{2+}$ in $\mathrm{SnO}$, or from a mixed oxide formed during the preparation. The rather high $\mathrm{Pd} / \mathrm{Sn}$ ratio in the as-prepared sample 1 points to a lower Pd dispersion, since the majority of the active metal is located on the top of the support characterized by very low BET surface area (Table 1). Reduction in $\mathrm{H}_{2}$ leads to $\mathrm{Pd}$ in two different states: the major part of the metal is reduced to metallic Pd with an electron binding energy of $335.8 \mathrm{eV}$, while some of the $\mathrm{Pd}$ atoms remain oxidized with a binding energy of $336.6 \mathrm{eV}$. Since the value of $335.8 \mathrm{eV}$ is significantly higher than $335.1 \mathrm{eV}$, known as a reference value for metallic Pd, the formation of surface $\mathrm{PdO}$ at large $\mathrm{Pd}$ particles may be supposed. For the $\mathrm{Sn}$ state of the same sample 1 in the $\mathrm{H}_{2}$ environment, only one peak at $487.6 \mathrm{eV}$ could be observed (Fig. 2b; Table 2), which surprisingly indicates oxidation of $\mathrm{Sn}^{2+}$ to $\mathrm{Sn}^{4+}$, even under mild reducing conditions. This transformation could be explained by electron transfer from a part of the lower charged $\mathrm{Sn}$ atoms to $\mathrm{Pd}(\mathrm{O})$, contributing in such a way to the amount of $\mathrm{Pd}$ reduced by $\mathrm{H}_{2}$. Such a $\mathrm{Sn}-\mathrm{Pd}$ electron transfer, as an indication of metalsupport interaction (MSI), is followed by $\mathrm{Pd} / \mathrm{Sn}$ ratio decreases during the $\mathrm{H}_{2}$ treatment from 2.44 to 1.45 (Table 2). That is to say, $\mathrm{Pd}$ originally segregated at $\mathrm{SnO}_{2}$ surface diffuse to the bulk of the support. This process is sustained due to differences in surface free energy values, as 2.1 and $0.7 \mathrm{~J} / \mathrm{m}^{2}$ for Pd and Sn, respectively (Campbell 1997). The reducing conditions, however, do not contribute to a significant change of the active metal distribution, a high portion of Pd still staying agglomerated on the top of low surface $\mathrm{SnO}_{2}$.

The $\mathrm{Pd} / \mathrm{Sn}$ ratio of calcined sample 2 is markedly lower than on corresponding sample 1 , and there are no further changes in this regard during reduction in $\mathrm{H}_{2}$ (Table 2). Obviously $\mathrm{Pd}$ is already widely enclosed in the $\mathrm{SnO}_{2}$ matrix during the preparation by the modified sol-gel method embracing early contact of the support and metal precursors, followed by high calcination temperature. Only a few part of the Pd is located in the near-surface region detectable by XPS, which might be essential for the catalytic properties. As seen from Fig. $2 \mathrm{a}$ only one Pd state exists in sample 2 regardless of the post-treatment. A peak shift from 337.4 to $336.1 \mathrm{eV}$ is observed after the treatment in $\mathrm{H}_{2}$, indicating Pd reduction but not to the metallic state. This can be explained either by the formation of a surface $\mathrm{Pd}$ oxide, or by a strong interaction between $\mathrm{Pd}$ and $\mathrm{Sn}$, which may stabilize partially oxidized Pd. TEM investigations described later show an intimate contact between $\mathrm{SnO}_{2}$ and $\mathrm{Pd}$ crystallites supporting the second scenario of a strong interaction between $\mathrm{Pd}(\mathrm{O})$ and $\mathrm{SnO}_{2}$. For Sn two different states are observed in the fresh sample 2: a major peak at $486.2 \mathrm{eV}$ and a shoulder at $487.9 \mathrm{eV}$. After the treatment in $\mathrm{H}_{2}$, only one peak at $487.0 \mathrm{eV}$ is visible, indicating the presence of multivalent $\mathrm{Sn}$ possibly in interaction with $\mathrm{Pd}$. The slightly lower $\mathrm{Sn} 3 \mathrm{~d}$ value in sample 2 in comparison to sample 1 may point to a more pronounced MSI effect in the first case. In summary, based on the XPS results it can be concluded that only a minor part of $\mathrm{Pd}$ is strongly interacting with the $\mathrm{SnO}_{2}$ support in sample 1 , whereas an interaction for nearly all $\mathrm{Pd}$ atoms with the support can be proposed for sample 2 .

UV-vis-DR spectra of as-prepared samples and after reduction in $\mathrm{H}_{2}$ both recorded at $20^{\circ} \mathrm{C}$ are presented in Fig. 3. For samples examined in air (Fig. 3a), an intense band at $280 \mathrm{~nm}$ in case of sample 2 can be attributed to $\mathrm{Pd}-\mathrm{O}$ charge transfer, and is characteristic of welldispersed Pd in interaction with an oxide support (Feio et al. 2007; Ivanova et al. 2010). The same band around $280 \mathrm{~nm}$, however, has been claimed previously to be due to

Table 1 Textural and structural properties of catalyst samples

\begin{tabular}{llclll}
\hline Catalyst & $\begin{array}{l}\text { Pd content } \\
(\text { mass\%) }\end{array}$ & $\begin{array}{l}\mathrm{S}_{\mathrm{BET}} \\
\left(\mathrm{m}^{2} / \mathrm{g}\right)\end{array}$ & $\begin{array}{l}\text { Mean pore } \\
\text { diameter }(\mathrm{nm})\end{array}$ & $\begin{array}{l}\text { Total pore } \\
\text { volume }\left(\mathrm{cm}^{3} / \mathrm{g}\right)\end{array}$ & $\begin{array}{l}\text { Crystalline size } \\
\text { of } \mathrm{SnO}_{2}^{\mathrm{a}}(\mathrm{nm})\end{array}$ \\
\hline 1 & 4.8 & 3.2 & 8.7 & 0.01 & 36 \\
2 & 6.1 & 35.6 & 13.0 & 0.12 & 14 \\
\hline
\end{tabular}

${ }^{a}$ Calculated from XRD lines broadening using Scherer formula 

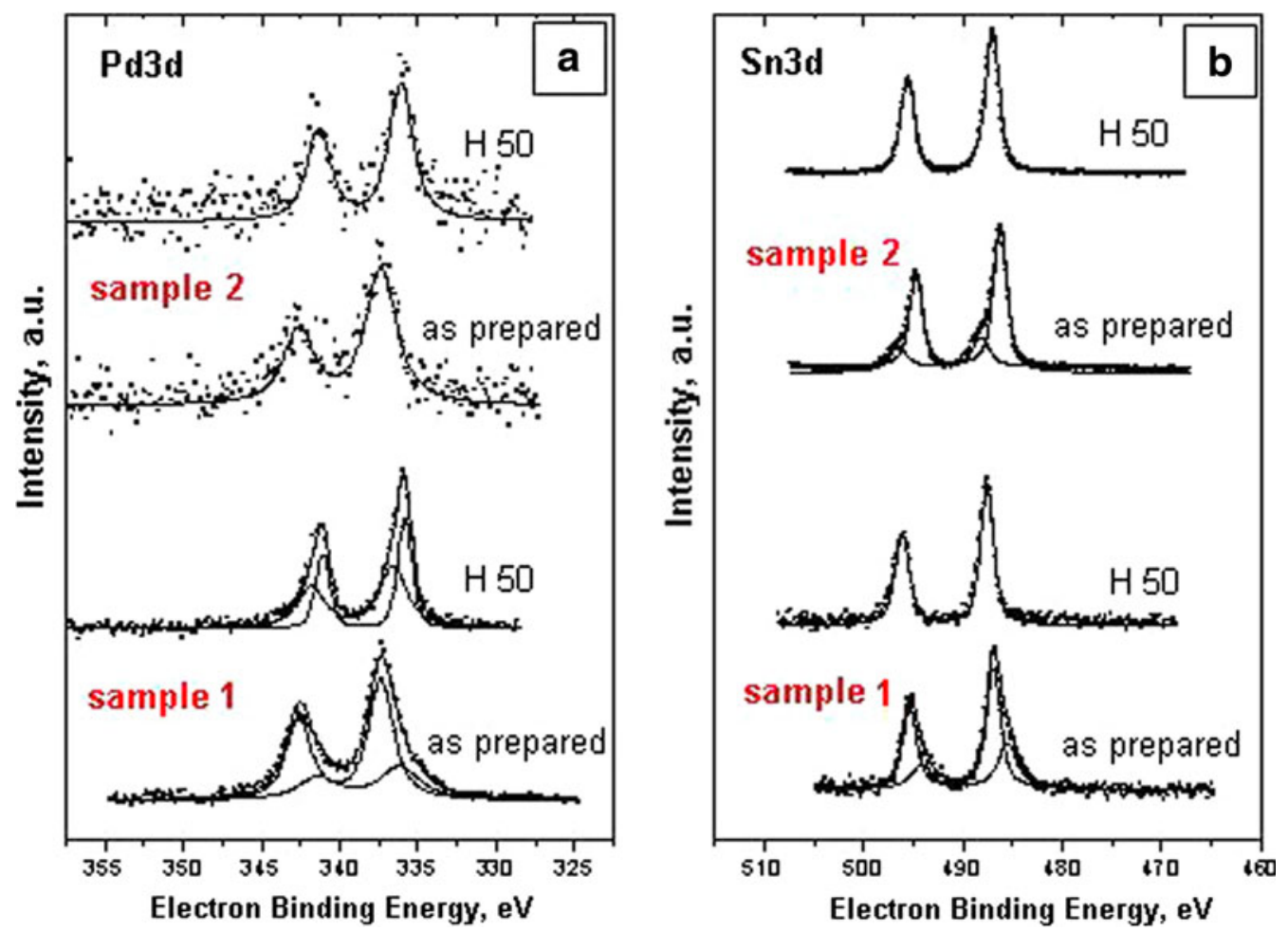

Fig. 2 XPS spectra of $\operatorname{Pd} 3 \mathrm{~d}(\mathbf{a})$ and $\operatorname{Sn} 3 \mathrm{~d}(\mathbf{b})$ states of samples 1 and 2 before and after treatment in $\mathrm{H} 2$ at $50^{\circ} \mathrm{C}$

Table 2 Electron binding energies of $\mathrm{Pd}$ and $\mathrm{Sn}$ and $\mathrm{Pd} / \mathrm{Sn}$ ratios in the near-surface region

\begin{tabular}{|c|c|c|c|c|c|c|}
\hline \multicolumn{2}{|c|}{ Sample } & \multicolumn{4}{|c|}{ Electron binding energy $(\mathrm{eV})$} & \multirow{3}{*}{$\begin{array}{l}\mathrm{Pd} / \mathrm{Sn} \\
\text { ratio }\end{array}$} \\
\hline & & \multicolumn{2}{|c|}{$\operatorname{Pd} 3 d 5 / 2$} & \multicolumn{2}{|c|}{ Sn $3 d 5 / 2$} & \\
\hline \multirow[t]{2}{*}{1} & Calcined & 336.1 & 337.4 & 485.6 & 486.9 & \\
\hline & H 50 & 335.8 & 336.6 & & & 1.45 \\
\hline \multirow[t]{2}{*}{2} & Calcined & \multicolumn{2}{|c|}{337.4} & 486.2 & 487.9 & 0.05 \\
\hline & H 50 & \multicolumn{2}{|c|}{336.1} & \multicolumn{2}{|c|}{487.0} & 0.04 \\
\hline
\end{tabular}

The doublet separation between the $5 / 2$ and $3 / 2$ peaks is $5.2 \mathrm{eV}$ for $\mathrm{Pd} 3 \mathrm{~d}$ and $8.5 \mathrm{eV}$ for $\mathrm{Sn} 3 \mathrm{~d}$

chlorine decoration of $\mathrm{Pd}$, i.e., to a $\mathrm{Pd} \rightarrow \mathrm{Cl}$ charge transfer and formation of a superficial $\mathrm{Pd}_{X} \mathrm{O}_{Y} \mathrm{Cl}_{Z}$ complex (Gaspar and Dieguez 2000). A broad band in the $\mathrm{d}-\mathrm{d}$ transition region from 450 to $500 \mathrm{~nm}$ (maximum at about $490 \mathrm{~nm}$ ), which is much more pronounced in the spectra of sample 1 , has been attributed to bulk $\mathrm{PdO}$ particles of different size with no interaction with the support (Alegre et al. 2006; Ivanova et al. 2010). This may indicate larger $\mathrm{PdO}$ particles ( $C^{\prime}$ onsul et al. 2006) sitting on the edge of the support of sample 1, which is a scenario that suites well to the lower $\mathrm{Pd}(\mathrm{O})$ dispersion found by XPS of the same sample (Table 2). After exposure to $\mathrm{H}_{2}$ spectra of catalyst samples are even more different (Fig. 3b). The absence of the band at $280 \mathrm{~nm}$, responsible for charge transfer of oxygen from the support to $\mathrm{d}$ orbital of $\mathrm{Pd}$, may be attributed to the presence of large metallic Pd particles in the sample 1
(Ivanova et al. 2010). This is an additional proof of low extent of reached metal-support interaction in sample 1, allowing Pd particles, sitting agglomerated at $\mathrm{SnO}_{2}$ surface, an easy reduction. In contrast, Pd particles of sample 2 exposed to $\mathrm{H}_{2}$ demonstrate further $\mathrm{Pd}-\mathrm{O}$ charge transfer as characteristic of $\mathrm{Pd}-\mathrm{SnO}_{2}$ interaction, due to $\mathrm{Pd}$ position remaining deeply embedded in the $\mathrm{SnO}_{2}$ matrix. As pointed by Barrabes and Sá (2011) for conventional supported $\mathrm{Pd}-\mathrm{Sn}$ catalyst, close proximity between noble metal and promoter is essential to stabilize the later in its lower oxidation state which is the active phase.

Morphological and textural characterization

SEM pictures presented in Fig. $4 \mathrm{~b}$ reflect morphological properties of sample 2. Namely, its surface is characterized 

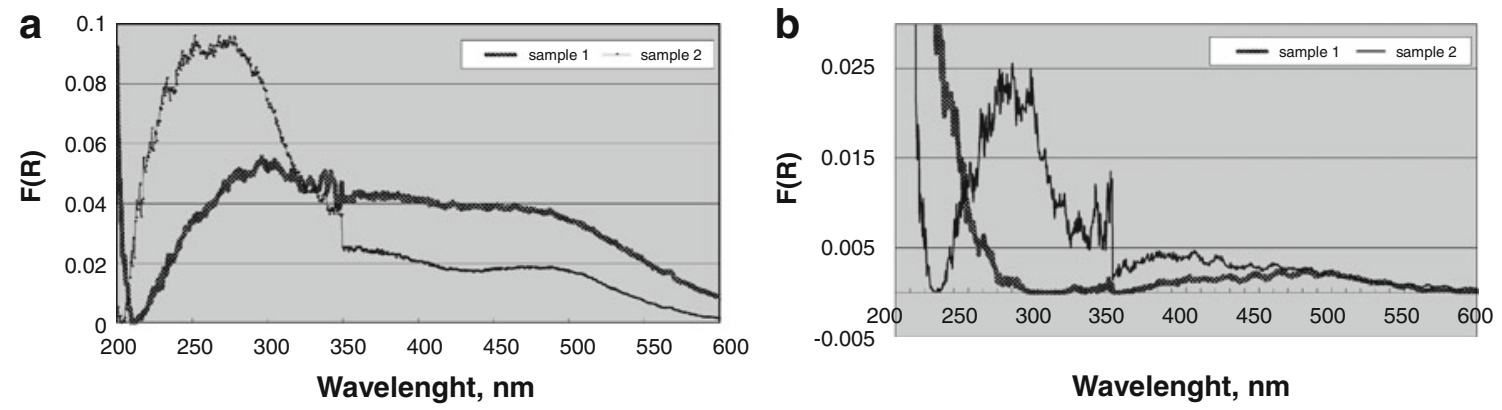

Fig. 3 Kubelka-Munk function $\left(F(R)=\left(1 \_R 2\right) / 2 R\right)$ of catalysts 1 and 2 examined in air (a) and in hydrogen (b), both at $20^{\circ} \mathrm{C}$
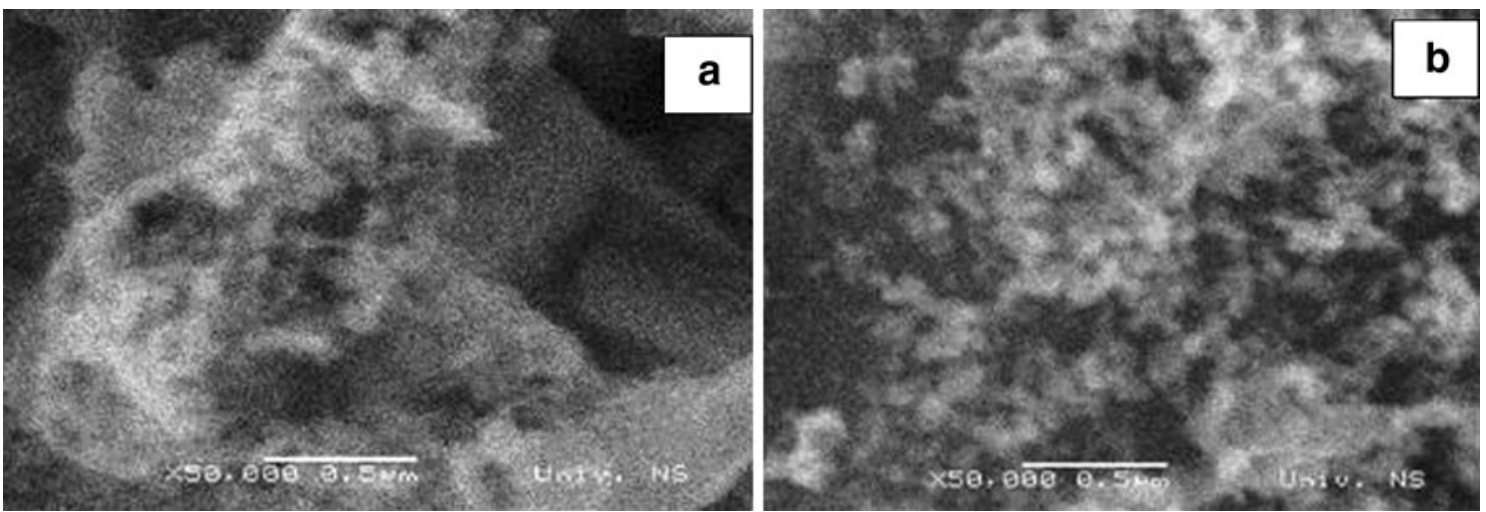

Fig. 4 SEM images of catalyst samples 1 (a) and 2 (b)

by a raft spongy structure indicating crystallites of very small size, some of them even on nanometer scale. In contrast, the surface morphology of sample 1 (Fig. 4a) shows clearly distinct phases, i.e. more or less smooth planes which might correspond to the support and some morphologically completely different structure sitting on the top of the previous. Such a composition together with plane smoothness does not promise too much in favor of good textural characteristics. Indeed, as follows from pore distribution curves given in Fig. 5 and corresponding data shown in Table 1, catalyst sample 1 failed in terms of all textural properties relative to those of sample 2 . The main pore diameter of sample 2 is cleary visible as well defined in a mesoporous range at around $30 \mathrm{~nm}$, while curve maximum showing size of dominant pores in Fig. 5a is not very clear. That is to say, there are some fractions of mesopores of the same size as in the previous sample; however, their absolute number is low which is confirmed by the volume of $\mathrm{N}_{2}$ adsorbed. Both samples also pose the small fraction of the pores of $2-3 \mathrm{~nm}$. In short, there is more developed pore structure for sample 2 compared to sample 1, which is in accordance with extremely low surface area of the last (Table 1) and its significantly lower total pore volume, i.e. $0.01 \mathrm{~cm}^{3} / \mathrm{g}$ compared to $0.12 \mathrm{~cm}^{3} / \mathrm{g}$ for the catalyst of better performances. As will be seen later, this might have a detrimental effect on the catalyst efficiency, which is in accordance with the results of previous investigations showing high specific surface area of $\mathrm{Pd} / \mathrm{SnO}$ system as essential for high activity (Takeguchi et al. 2003). As shown in Fig. 5c, d adsorption-desorption isotherm profiles form hysteresis loops indicating no distinct differences in shape of related pores, but in their size. Pores seem to be formed as narrow cracks and fissures arising from spaces between parallel plates (Sing and Rouquerol 1997). However, adsorptiondesorption isotherms given by Fig. $5 \mathrm{c}$ do not exhibit limiting adsorption at high relative pressure, indicating not well-defined mesopore structure but the structure shifted to micropores range. It has to be mentioned, however, that LTNA applied to surfaces having very low surface area, as in the case of sample 1 , is on the edge of the applied method sensitivity.

TEM micrographs presented in Fig. 6 not only confirm the previous statement of different surface (support) morphologies of the examined samples, but also prove diversity in their Pd distribution. Sample 1 shows an intense structural change upon reduction. The calcined sample is characterized by big support crystallites covered by Pd of different particle sizes and shapes. EDXS investigations of some free-standing Pd-containing areas give hints for PdO. 

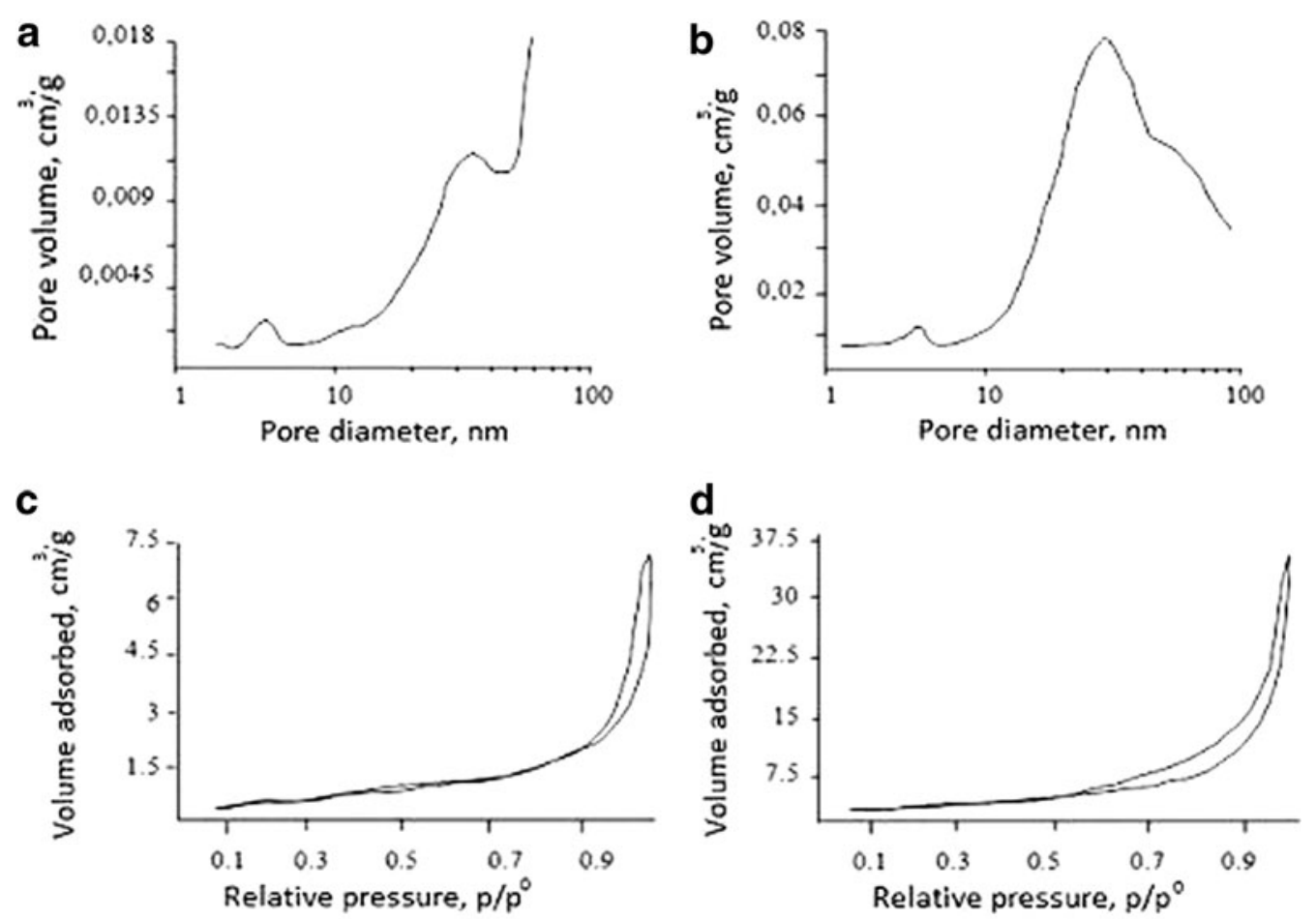

Fig. 5 Pore size distribution of sample 1 and $2(\mathbf{a}, \mathbf{b})$, and corresponding adsorption-desorption isotherms (c, d)

After reduction very big Pd particles accompanied by minor agglomerates of support particles were found. The image in Fig. 6b shows some of these support particles on the top of a Pd-containing structure with a length of some $100 \mathrm{~nm}$.

In contrast, TEM images of sample 2 (Fig. $6 \mathrm{c}, \mathrm{d}$ ) contain well-formed round particles with diameters of $10-20 \mathrm{~nm}$ of both support and the noble metal. These phases are very well mixed providing conditions for a proper contact. Although TEM identification of the Pd and $\mathrm{SnO}_{2}$ phases only by contrast was not possible, yet EDXS investigations at different position of the sample, as marked in the images of Fig. 6, provided information on the nature of the particles. However due to the overlap with the oxide support, it is not possible in every case to distinguish between $\mathrm{Pd}$ and $\mathrm{PdO}$ phases. As in the case of previous sample, $\mathrm{H}_{2}$ treatment of sample 2 leads to the reduction of the noble metal. There are, however, almost no morphological differences between calcined and reduced Pd states, indicating recrystallization of Pd being much less pronounced than in the case of sample 1 .

\section{Catalytic tests}

Catalytic performances of samples in terms of residual $\mathrm{NO}_{3}{ }^{-}$content with time-on-stream, and absolute production of $\mathrm{NH}_{4}{ }^{+}$, i.e. corresponding selectivities calculated at the end of the reaction are given in Fig. 7. Catalyst 2 performs very well, reaching an acceptable level of residual nitrates yet after $2 \mathrm{~h}$, while sample 1 shows very low activity (Fig. 7a). Selectivity of the catalyst sample 2 is better too (Fig. 7b). It produces a slightly higher total amount of $\mathrm{NH}_{3}$ than sample 1 (2.45 ppm in comparison to $1.98 \mathrm{ppm}$ ), however, considering the total amount of $\mathrm{NO}_{3}{ }^{-}$ removed the selectivity to $\mathrm{NH}_{3}$ of sample 2 comes to only $9 \%$, relative to $68 \%$ of sample 1 . In addition, no $\mathrm{NO}_{2}{ }^{-}$ formation was observed during the hydrodenitration reaction (Fig. 7a), which can be attributed to the reaction conditions, i.e. high Pd loading which kinetically favors the second step of the consecutive hydrodenitration reaction (Harold et al. 1993). Moreover, regular well-developed pore structure of sample 2 contributes for its favorable low selectivity toward $\mathrm{NH}_{4}{ }^{+}$compared to sample 1. Extremely low surface area and not well-defined pore structure of the later catalyst affect the accessibility of the active sites and drastically influence its detrimental catalytic activity. Generally known fact that selectivity is strongly determined by the concentration gradients of the reactants and products developed along the catalyst particle holds in particular for the consecutive reaction of $\mathrm{NO}_{3}{ }^{-}$hydrogenation. The fast diffusion of the products from the catalyst particle is an indispensable requirement to avoid the further not desirable reaction pathways. In general a hierarchical pore system, consisting of micropores connecting individual active sites, 


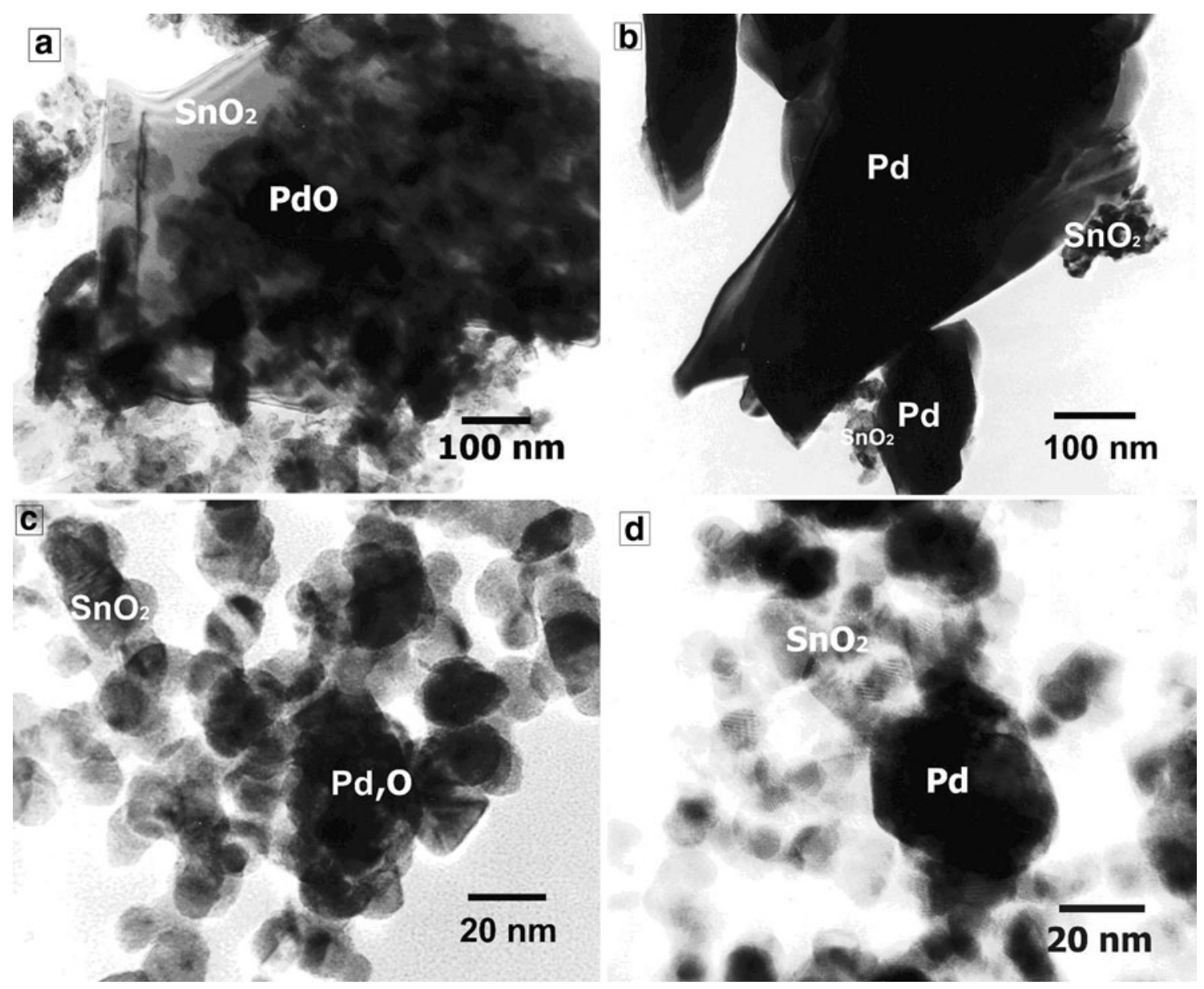

Fig. 6 TEM micrographs of sample 1 (calcined, a; reduced, b) and sample 2 (calcined, c; reduced, d)

mesopores (transport pores) between the particles and finally macropores in the catalyst pellet is considered to be advantageous for good activity and selectivity (Schmidt 2009). Thus, the diffusion limitation caused by absence of mesopores in sample 1 shifts conversion toward nondesirable $\mathrm{NH}_{4}{ }^{+}$and our results strongly support the fact that the gradients of produced $\mathrm{OH}^{-}$species in fact govern the reaction toward low selective pathway.

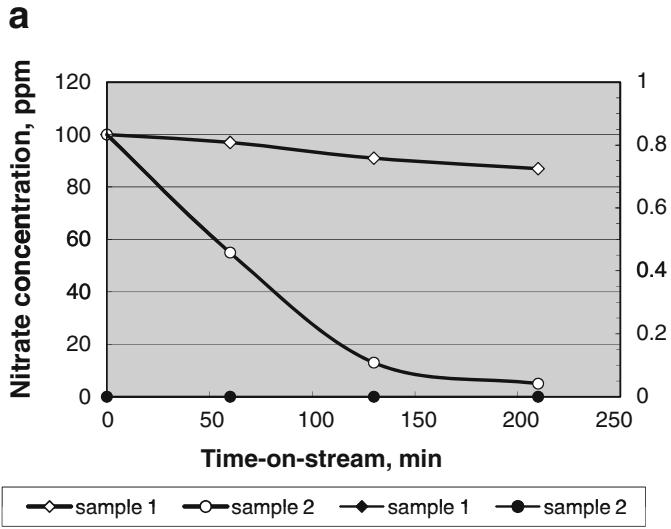

Fig. 7 Catalyst activity with time-on-stream (a) (empty symbols, $\mathrm{NO}_{3}{ }^{-}$; filled symbols, $\mathrm{NO}_{2}{ }^{-}$) and selectivity at the end of the reaction (215 $\mathrm{min}$ ) (b) (white bars to the left $Y$ axis correspond to the total

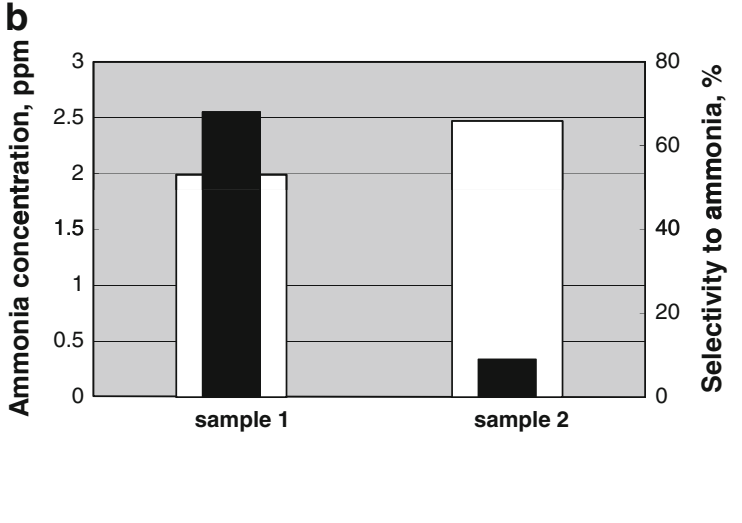

amount of $\mathrm{NH}_{3}$ produced; black bars to the right $Y$ axis correspond to selectivity to $\mathrm{NH}_{3}$ ) 
Structure-reactivity relationships

Although there is some difference in Pd content of the two samples (Table 1), this cannot be the reason for such big activity discrepancy between them. That is to say, almost $5 \%$ Pd loading achieved in sample 1 should have been more than enough for the catalyst to perform considerable activity. Thus, the rather low catalytic performance of sample 1 is first of all the consequence of its structural properties, i.e. unfavorable Pd dispersion, but might partly result from its textural characteristics as well (Table 1). First of all there is a substantially lower BET surface area and total pore volume of sample 1 as well as lower mean pores diameter. Namely, although both samples are characterized by a pore structure in beneficial mesopore domain, the mean pores diameter of sample 1 is smaller, possibly imposing diffusion restrictions. The problem of mass transfer phenomena in denitration catalysts has been discussed in the literature in light of building of unfavorable $\mathrm{pH}$, pointing out advantages of large pores (D'Arino et al. 2004). This postulation is in line with high selectivity of sample 1 to $\mathrm{NH}_{3}$ (Fig. 7b) as a possible consequence of diffusion constrains occurring in its small pores. Consequently, unexpectedly high $\mathrm{pH}$ value might have been achieved relative to the beneficial applied reaction conditions, i.e. provided high $\mathrm{CO}_{2}$ flow. The advantage of alkaline conditions for $\mathrm{NH}_{4}^{+}$production has been proven earlier (Gavagnin et al. 2002; Prusse et al. 2000). In favor of selectivity results it has to be mentioned that $\mathrm{NO}_{2}{ }^{-}$ presence in neither of catalytic runs was noticed, conforming the previous finding using a similar catalyst (D'Arino et al. 2004). In line with the former, it seems that both favorable structural properties, characterized by good Pd dispersion due to beneficial Pd-Sn interaction, and textural characteristics, portrayed as optimal pore size and BET surface area, might be clues for superior activity and selectivity of sample 2. Other authors also claim importance of high-developed surface for high denitration activity, suggesting co-precipitation in the case of PdO$\mathrm{SnO}_{2}$ catalyst synthesis as a favorable preparation method leading to this goal (Takeguchi et al. 2003).

At the moment the mechanism of water denitration in the presence of $\mathrm{H}_{2}$ on noble metal-supported catalyst is still not completely understood (Barrabes and Sá 2011). Traditional mechanism advocates occurrence of consecutive reaction steps at different entities of bimetallic catalysts, i.e. $\mathrm{NO}_{3}{ }^{-}$reduction to $\mathrm{NO}_{2}{ }^{-}$on $\mathrm{Pd}-\mathrm{P}(\mathrm{P}=\mathrm{Cu}, \mathrm{Sn}, \mathrm{In}, \mathrm{Zn})$ and further hydrogenation of $\mathrm{NO}_{2}{ }^{-}$to either $\mathrm{N}_{2}$ or $\mathrm{NH}_{4}{ }^{+}$ on Pd alone (Harold et al. 1993). However, there are disagreements on identity of active sites, mainly related to oxidation state of the promoter (Epron et al. 2001; Gao et al. 2003). Next to plenty of data suggesting inability of unpromoted noble metals to remove $\mathrm{NO}_{3}{ }^{-}$(Epron et al.
2001; Gavagnin et al. 2002; Prusse et al. 2000), there are also evidence of optimal metal/promoter ratio as necessary for the reaction. Thus by increasing the $\mathrm{Pd} / \mathrm{Sn}$ ratio in a bimetallic $\mathrm{Pd}-\mathrm{Sn} / \mathrm{Al}_{2} \mathrm{O}_{3}$ catalyst, the lowest activity in $\mathrm{NO}_{3}{ }^{-}$reduction has been found for the highest $\mathrm{Pd} / \mathrm{Sn}=12$ ratio, accompanied also by the highest $\mathrm{NH}_{4}^{+}$production (lowest selectivity) (Prusse et al. 2000). Authors have proposed a bimetallic $\mathrm{Pd}-\mathrm{Sn}$ site responsible for an advantageous activity, and Pd alone for the low selectivity. For a supported Pd-Sn catalyst, ability for both $\mathrm{NO}_{2}{ }^{-}$and $\mathrm{NO}_{3}{ }^{-}$reduction has been directly linked to the amount of reducible Sn in interaction with Pd (Garron et al. 2005).

New literature data, however, suggest unpromoted monometallic Pd-supported catalyst as active in denitration reaction, in which reduced support sites perform the first reaction step. The last has been suggested in case of $\mathrm{SnO}_{2}$ (D'Arino et al. 2004; Gavagnin et al. 2002), $\mathrm{TiO}_{2}$ (Sá et al. 2005) and $\mathrm{CeO}_{2}$ (Epron et al. 2002) used as catalyst supports. In case of $\mathrm{SnO}_{2}$ its easy reduction has been advocated extensively (Gavagnin et al. 2002; Lorenz et al. 2010; Mäki-Jaskari and Rantala 2003; Safonova et al. 2000). Thus, both $\mathrm{SnO}_{2}$ and $\mathrm{PdO}$ reduction at the grain boundaries, occurring after annealing at $380^{\circ} \mathrm{C}$ even in an inert atmosphere, has been reported in the case of thin film of $\mathrm{Pd}(7 \%)-\mathrm{SnO}_{2}$ alloy (Safonova et al. 2000). Deactivation of $\mathrm{SnO}_{2}$ surface by means of $\mathrm{SnO}_{X}$ coverage has been observed in $\mathrm{Pd} / \mathrm{SnO}_{2}$ catalyst for methanol dehydrogenation after reduction at low temperature, while metallic $\mathrm{Sn}$ has been formed yet at $200^{\circ} \mathrm{C}$ (Lorenz et al. 2010). In case of $\mathrm{Pd} / \mathrm{SnO}_{2}$ catalyst, possibility of existence of active site in the form of $\mathrm{SnO}_{X}(X<2)$, formed on the $\mathrm{Pd} / \mathrm{SnO}_{2}$ interface, has been suggested (Gavagnin et al. 2002). Since the highest initial rate of $\mathrm{NO}_{3}{ }^{-}$depletion was observed at the lowest reduction temperature, occurrence of partially reduced $\mathrm{SnO}_{X}$ has been proposed even at room temperature (Gavagnin et al. 2002). This might be realized through a deep nonstoichiometric binding of $\mathrm{Pd}$ to $\mathrm{SnO}_{2}$ which can result in $\mathrm{O}$-atom release, promoting in that way the $\mathrm{SnO}_{X}$ sites reactivity (Mäki-Jaskari and Rantala 2003).

Subsequently and in accordance with the results from the present investigation, neither $\mathrm{SnO}_{2}$ nor Pd as separated phases can effectively contribute to water denitration activity of $\mathrm{Pd} / \mathrm{SnO}_{2}$ catalytic system. Only when $\mathrm{SnO}_{2}$ and $\mathrm{Pd}(\mathrm{O})$ phases are strongly interacted efficient active sites are formed, like in the case of sample 2. These may be either of a bimetallic or monometallic form, although for development of the former yet a bimetallic Sn-Pd interaction is the prerequisite. Thus, XRD-line broadening in the case of sample 2 at $d=0.264 \mathrm{~nm}$ (Fig. 1), characteristic of both $\mathrm{SnO}_{2}$ and $\mathrm{PdO}$ phases, might be the result of partial dissolution of $\mathrm{Pd}$ species into the $\mathrm{SnO}_{2}$ lattice resulting in a higher number of defects. This might have happened in the calcination procedure of sample 2, since 
the Pd precursor has experienced a considerably higher temperature than in the case of sample $1\left(700\right.$ vs. $\left.400^{\circ} \mathrm{C}\right)$. Indeed, an early active metal-support embracement during the modified sol-gel method, followed by the high oxidation temperature, might be the driving force for $\mathrm{Pd}^{2+}$ ions to diffuse into the $\mathrm{SnO}_{2}$ matrix. As mentioned before, such close proximity plays a crucial role in stabilization of lower oxidation state of promoter in case of bimetallic Pd-Sn catalyst (Barrabes and Sá 2011). Recently a peculiar behavior of $\mathrm{Pd} / \mathrm{SnO}_{2}$ has been reported by means of $\mathrm{Pd}$ particle intrusion into the support upon reduction (Kamiuchi et al. 2010). The phenomenon has found a ground in a particle encapsulation mechanism by migration of oxide used as a support (Tauster and Fung 1978) and is attributed to both strong metal-support interaction (SMSI) and hydrogen storage capacity of $\mathrm{Pd}$ (Kamiuchi et al. 2010). This is in agreement with $\operatorname{Pd}(\mathrm{O})-\operatorname{Sn}(\mathrm{O})$ interaction which according to all here presented results occur in both samples but are much more prominent in sample 2 . Namely, high Pd dispersion before and after the treatment in $\mathrm{H}_{2}$ due to SMSI in sample 2, indicated by XPS results (Table 2), is in accordance with $\mathrm{Pd}-\mathrm{O}$ charge transfer occurring even in the reducing conditions of $\mathrm{H}_{2}$. According to intensities of DRS bands shown in Fig. 3b, it is diametrically opposite to sample 1 in which only reduced $\mathrm{Pd}$ can be identified. Next to the extreme agglomeration of Pd onto the surface of support of catalyst sample 1 shown by both XPS and TEM it is an additional proof of low Pd dispersion in the particular case. On the contrary, good Pd dispersion of the sample 2 was confirmed by TEM micrographs showing very intimate contact of the support and metal particles, both on the nanosize level. In addition, XPS data indicate existence of partially oxidized Pd stabilized by SMSI between Pd and Sn. After the treatment in $\mathrm{H}_{2}$ there is an indication of the presence of multivalent $\mathrm{Sn}$ which possibly interacted with $\mathrm{Pd}$, although this interaction may be weak. This multivalent Sn may consist of partly reduced Sn oxide, as claimed by Safonova et al. (2000), acting as active site and being responsible for pronounced activity of sample 2 .

The fact that in neither of catalytic runs performed in this work $\mathrm{NO}_{2}{ }^{-}$ions were found (Fig. 7a) does not exclude the reaction route comprising $\mathrm{NO}_{3}{ }^{-}$reduction to $\mathrm{NO}_{2}{ }^{-}$. It may happen on some $\mathrm{SnO}_{X}(-\mathrm{PdO})$ species acting as active sites but might not be noticed due to different kinetics throughout the reaction. That is to say, the huge Pd loading applied in both catalyst samples might make the $\mathrm{NO}_{2}{ }^{-}$to $\mathrm{N}_{2}$ or $\mathrm{NH}_{3}$ conversion very rapid relative to rate of $\mathrm{NO}_{3}{ }^{-}$ formation. Similar absence of $\mathrm{NO}_{2}{ }^{-}$in the presence of high loading (5 wt \%) Pd-supported catalyst has been observed earlier (Dodouche et al. 2009). Therefore, the activity of catalyst sample 1 might have been suppressed by banning the first step of the consecutive reaction due to lack of active sites in the form of partly reduced Sn oxide closely connected to PdO. Close contact with Pd may be necessary for the primary $\mathrm{SnO}_{X}$ formation which may be located on the support-metal interphase. Therefore, a high Pd dispersion as achieved in sample 2 is very important, since it might be directly proportional to the extent of the formed interphase, i.e. to probability for $\mathrm{SnO}_{X}(-\mathrm{PdO})$ active sites formation.

In contrast, TEM, XPS and DRS results of sample 1 suggest a pronounced $\mathrm{Pd}$ segregation at the $\mathrm{SnO}_{2}$ surface and a quite unstable $\mathrm{Pd}-\mathrm{O}(\mathrm{Sn})$ interaction even in mild hydrogen conditions. It seems that $300^{\circ} \mathrm{C}$ higher calcination temperature to which the active phase precursor of sample 2 was subjected in the procedure of its preparation substantially influences the position and size of $\mathrm{Pd}(\mathrm{O})$ particles. Accordingly, 5-10 times smaller $\mathrm{PdO}$ aggregates in $\mathrm{Pd} / \mathrm{Al}_{2} \mathrm{O}_{3}$ has been found after calcination at $800^{\circ} \mathrm{C}$ relative to those particles calcined at $500^{\circ} \mathrm{C}$ (Ivanova et al. 2010). Besides, as shown in Table 2 , some unexpected behavior such as oxidation to a higher $\mathrm{Sn}$ valence state occurs in the same sample as a consequence of Sn-Pd interaction. In theory $\mathrm{SnO}_{2}$ is a typical oxidation catalyst working by a Mars-van Krevelen mechanism, i.e. a specie is oxidized by consuming lattice oxygen of the catalyst which in turn is re-oxidized by gas-phase $\mathrm{O}_{2}$ (Batzill and Diebold 2005). Similarly, O-atom release from $\mathrm{SnO}_{2}$ due to strong interaction between $\mathrm{Pd}$ and $\mathrm{SnO}_{2}$ has been claimed as a prerequisite for the formation of $\mathrm{SnO}_{X}$ with high reactivity (Mäki-Jaskari and Rantala 2003). In the particular case of the present investigation, however, according to both XPS and DRS results obtained in $\mathrm{H}_{2}$, there is a charge transfer from Sn to Pd indicating some interaction. How far this interaction can go depends on both the $\mathrm{Pd} / \mathrm{Sn}$ ratio and oxidation potential of the atmosphere. Thus, Pd-Sn alloy formation has been reported when the structure consisted of more than $6 \mathrm{Pd}$ layers covering $\mathrm{SnO}_{2}(110)$ following annealing at temperatures as low as $400^{\circ} \mathrm{C}$ (Batzill and Diebold 2005). Although the obtained XRD results from this work show no hint for Sn$\mathrm{Pd}$ solid solution in ether of catalyst samples, the high $\mathrm{Pd} /$ Sn ratio observed in sample 1 does not exclude formation of such a species either.

\section{Conclusion}

The modified sol-gel method assuming simultaneous acidic complexation of both the metal and support precursors results in a catalyst with beneficial structural, textural and morphological properties. These are portrayed as very high BET surface area and pores volume, as well as existence of uniform nanosize particles of both support and the noble metal providing conditions for a proper 
interaction. The metal particles are quite stable upon reduction due to SMSI available by very well-distributed $\mathrm{Pd}$ among $\mathrm{SnO}_{2}$ support. Thus, Pd strongly bounded to the support helps formation of partly reduced $\mathrm{SnO}_{X}$ acting as active site, formation of which may be limited exactly to the support-metal interphase. SMSI and related high metal dispersion are significant as being directly proportional to the degree of the interphase formation. At the same time mesoporous texture of the same $\mathrm{Pd} / \mathrm{SnO}_{2}$ catalyst is crucial for its selectivity, providing conditions for advantageous $\mathrm{pH}$ environment unfavorable for $\mathrm{NH}_{4}{ }^{+}$formation.

Acknowledgments This work was made possible by supports of DAAD foundation, Bohn and Matica srpska, Novi Sad, Serbia. G.B. is highly grateful for DAAD fellowship at Leibniz-Institut für Katalyse, former Branch Berlin, Germany.

\section{References}

Alegre VV, da Silva MAP, Schmal M (2006) Catalytic combustion of methane over palladium alumina modified by niobia. Catal Commun 7:314-322

Barrabes N, Sá J (2011) Catalytic nitrate removal from water, past, present and future perspectives. Appl Catal B Environ 104:1-5

Batzill M, Diebold U (2005) The surface and materials science of tin oxide. Prog Surf Sci 79:47-154

Bhagwat M, Shah P, Ramaswamy V (2003) Synthesis of nanocrystalline $\mathrm{SnO}_{2}$ powder by amorphous citrate route. Mater Lett 57:1604-1611

Boskovic G, Zarubica RA, Kovacevic M, Putanov P (2008) Precursor memory effect determining structural properties of sulfated zirconia. J Therm Anal Calorim 91(3):849-854

C'onsul JMD, Peralta CA, Benvenutti EV, Ruiz JAC, Pastore HO, Baibich IM (2006) Direct decomposition of nitric oxide on alumina-modified amorphous and mesoporous silica-supported palladium catalysts. J Mol Catal A Chem 246:33-38

Caillaud F, Smith A, Baumard JF (1992) Inter-relationship between deposition temperature and morphology of $\mathrm{SnO}_{2}$ films deposited by a pyrosol process. Thin Solid Films 208:4-6

Campbell CT (1997) Ultrathin metal films and particles on oxide surfaces: structural, electronic and chemisorptive properties. Surf Sci Rep 27(1-3):1-111

D’Arino M, Pinna F, Strukul G (2004) Nitrate and nitrite hydrogenation with $\mathrm{Pd}$ and $\mathrm{Pt} / \mathrm{SnO}_{2}$ catalysts: the effect of the support porosity and the role of carbon dioxide in control of selectivity. Appl Catal B Environ 53:161-168

Dieguez A, Romano-Rodriguez A, Morante JR, Weimar U, Schweizer-Berberich M, Göpel W (1996) Morphological analysis of nanocrystalline $\mathrm{SnO}_{2}$ for gas sensor applications. Sens Actuators B 31:1-8

Dodouche I, Barbosa DP, Rangel MC, Epron F (2009) Palladium-tin catalysts on conducting polymers for nitrate removal. Appl Catal B Environ 93:50-55

EPA, http://water.epa.gov/drink/contaminants/index.cfm\#List. December 2010

Epron F, Gauthard F, Pin'eda C, Barbier J (2001) Catalytic reduction of nitrate and nitrite on $\mathrm{Pt}-\mathrm{Cu} / \mathrm{Al}_{2} \mathrm{O}_{3}$ catalysts in aqueous solution: role of the interaction between copper and platinum in the reaction. J Catal 198:309-318

Epron F, Gauthard F, Barbier J (2002) Catalytic reduction of nitrate in water on a monometallic $\mathrm{Pd} / \mathrm{CeO}_{2}$ catalyst. J Catal 206:363-367
Feio LSF, Hori CE, Damyanova S, Noronha FB, Cassinelli WH, Marques CMP, Bueno JMC (2007) The effect of ceria content on the properties of $\mathrm{Pd} / \mathrm{CeO}_{2} / \mathrm{Al}_{2} \mathrm{O}_{3}$ catalysts for steam reforming of methane. Appl Catal A General 316:107-116

Fliegel W, Behr G, Werner J, Krabbes G (1994) Preparation, development of microstructure, electrical and gas sensitive properties of pure and doped $\mathrm{SnO}$ powders. Sens Actuators B 18-19:474-477

Fraigi L, Lamas DG, Walsoe de Reca NE (1999) Novel method to prepare nanocrystalline $\mathrm{SnO}_{2}$ powders by a gel-combustion process. Nanostruct Mater 11(3):311-318

Freyberger TB, Erickson JW, Semancik S (1989) Chemical and electronic properties of $\mathrm{Pd} / \mathrm{SnO}_{2}(110)$ model gas sensors. Surf Interface Anal 14:83-89

Gao WL, Guan NJ, Chen JX, Guan XX, Jin RC, Zeng HS, Liu ZG, Zhang FX (2003) Titania supported Pd-Cu bimetallic catalyst for the reduction of nitrate in drinking water. Appl Catal B Environ 46:341-351

Garron A, Lazar K, Epron F (2005) Effect of the support on tin distribution in $\mathrm{Pd}-\mathrm{Sn} / \mathrm{Al}_{2} \mathrm{O}_{3}$ and $\mathrm{Pd}-\mathrm{Sn} / \mathrm{SiO}_{2}$ catalysts for application in water denitration. Appl Catal B Environ 59:57-69

Gaspar AB, Dieguez LC (2000) Dispersion stability and methylcyclopentane hydrogenolysis in $\mathrm{Pd} / \mathrm{Al}_{2} \mathrm{O}_{3}$ catalysts. Appl Catal A General 201(2):241-251

Gavagnin R, Biasetto L, Pinna F, Strukul G (2002) Nitrate removal in drinking waters: the effect of tin oxides in the catalytic hydrogenation of nitrate by $\mathrm{Pd} / \mathrm{SnO}_{2}$ catalysts. Appl Catal B Environ 38:91-99

Harold S, Vorlop KD, Tacke T, Sell M (1993) Development of catalysts for a selective nitrate and nitrite removal from drinking water. Catal Today 17:21-30

Ivanova AS, Slavinskaya EM, Gulyaev RV, Zaikovskii VI, Stonkus OA, Danilova IG, Plyasova LM, Polukhina IA, Boronin AI (2010) Metal-support interactions in $\mathrm{Pt} / \mathrm{Al}_{2} \mathrm{O}_{3}$ and $\mathrm{Pd} / \mathrm{Al}_{2} \mathrm{O}_{3}$ catalysts for CO oxidation. Appl. Catal. B: Environ. 97:57-71

Kakihana M (1996) Sol-gel preparation of high temperature superconducting oxides. J Sol Gel Sci Technol 6:7-55

Kamiuchi N, Muroyama H, Matsui T, Kikuchi R, Eguchi K (2010) Nano-structural changes of $\mathrm{SnO}_{2}$-supported palladium catalysts by redox treatments. Appl Catal A General 379:148-154

Lorenz H, Zhao Q, Turner S, Lebedev O, Van Tendeloo G, Klotzer B, Rameshan C, Pfaller K, Konzett J, Penner S (2010) Origin of different deactivation of $\mathrm{Pd} / \mathrm{SnO}_{2}$ and $\mathrm{Pd} / \mathrm{GeO}_{2}$ catalysts in methanol dehydrogenation and reforming: a comparative study. Appl Catal A General 381:242-252

Mäki-Jaskari M, Rantala T (2003) Density functional study of Pd adsorbates at $\mathrm{SnO}_{2}(110)$ surfaces. Surf Sci 537:168-178

Prusse U, Hahnlein M, Daum J, Vorlop KD (2000) Improving the catalytic nitrate reduction. Catal Today 55:79-90

Putanov P, Kis E, Boskovic G, Lazar K (1991) Effects of the method of preparation of $\mathrm{MgC}_{2} \mathrm{O}_{4}$ as a support precursor on the properties of iron magnesium oxide catalysts. Appl Catal 73: $17-26$

Ristic M, Ivanda M, Popovic S, Music S (2002) Dependence of nanocrystalline $\mathrm{SnO}_{2}$ particle size on synthesis route. J Non Cryst Solids 303:270-280

Sá J, Berger T, Föttinger K, Riss A, Anderson JA, Vinek H (2005) Can $\mathrm{TiO}_{2}$ promote the reduction of nitrates in water? J Catal 234:282-291

Sá J, Montero J, Duncan E, Anderson JA (2006) Bi modified Pd/SnO catalysts for water denitration. Appl Catal B Environ 73:98105

Safonova OV, Rumyantseva MN, Kozlov RI, Labeau M, Delabouglise G, Ryabova LI, Gaskov AM (2000) Two successive effects in the interaction of nanocrystalline $\mathrm{SnO}_{2}$ thin films with reducing gases. Mater Sci Eng B 77:159-166 
Schmidt W (2009) Solid catalysts on the nanoscale: design of complex morphologies and pore structures. ChemCatChem 1:53-67

Sing KSW, Rouquerol J (1997) Characterization of solid catalysts. In: Ertl G, Knozinger H, Weitkamp J (eds) Handbook of heterogeneous catalysis, vol 2. VCH-Wiley, Weinheim

Takeguchi T, Takeoh O, Aoyama S, Ueda J, Kikuchi R, Eguchi K (2003) Appl Catal A General 252:205-214
Tauster SJ, Fung SC (1978) Strong metal-support interactions: occurrence among the binary oxides of groups IIA-VB. J Catal 55:29-35

Wang C, Hu Y, Qian Y, Zhao G (1996) A novel method to prepare nanocrystalline $\mathrm{SnO}_{2}$. Nanostruct Mater 7:421-427

Zhang J, Gao L (2004) Synthesis and characterization of nanocrystalline tin oxide by sol-gel method. J Solid State Chem 177: $1425-1430$ 